\title{
BMJ Selective decontamination of the Open digestive tract and selective oropharyngeal decontamination in intensive care unit patients: a cost-effectiveness analysis
}

\author{
Evelien A N Oostdijk, ${ }^{1,2}$ G A de Wit, ${ }^{3,4}$ Marina Bakker, ${ }^{1}$ Anne Marie G A de Smet, ${ }^{5}$ \\ M J M Bonten, ${ }^{1,3}$ on behalf of the Dutch SOD-SDD trialists group
}

To cite: Oostdijk EAN, de Wit GA, Bakker M, et al. Selective decontamination of the digestive tract and selective oropharyngeal decontamination in intensive care unit patients:

a cost-effectiveness analysis BMJ Open 2013;3:e002529. doi:10.1136/bmjopen-2012002529

- Prepublication history for this paper are available online. To view these files please visit the journal online (http://dx.doi.org/10.1136/ bmjopen-2012-002529).

This work was presented in part at the 25th Annual Congress of the European Society of Intensive Care Medicine, Lisbon, Portugal, 13-17 October 2012.

Received 21 December 2012 Revised 27 January 2013 Accepted 7 February 2013

This final article is available for use under the terms of the Creative Commons Attribution Non-Commercial 2.0 Licence; see http://bmjopen.bmj.com

For numbered affiliations see end of article.

Correspondence to Dr Evelien AN Oostdijk; E.A.N.Oostdijk@umcutrecht.nl

\section{ABSTRACT}

Objective: To determine costs and effects of selective digestive tract decontamination (SDD) and selective oropharyngeal decontamination (SOD) as compared with standard care (ie, no SDD/SOD (SC)) from a healthcare perspective in Dutch Intensive Care Units (ICUs).

Design: A post hoc analysis of a previously performed cluster-randomised trial (NEJM 2009;360:20).

Setting: 13 Dutch ICUs.

Participants: Patients with ICU-stay of $>48 \mathrm{~h}$ that received SDD ( $n=2045)$, SOD $(n=1904)$ or SC $(\mathrm{n}=1990)$.

Interventions: SDD or SOD.

Primary and secondary outcome measures:

Effects were based on hospital survival, expressed as crude Life Years Gained (cLYG). The incremental costeffectiveness ratio (ICER) was calculated, with corresponding cost acceptability curves. Sensitivity analyses were performed for discount rates, costs of SDD, SOD and mechanical ventilation.

Results: Total costs per patient were $€ 41941$ for SC (95\% Cl €40 184 to $€ 43$ 698), $€ 40433$ for SOD (95\% $\mathrm{Cl} € 38838$ to $€ 42029)$ and $€ 41183$ for SOD $(95 \% \mathrm{Cl}$ $€ 39408$ to $€ 42$ 958). SOD and SDD resulted in crude LYG of +0.04 and +0.25 , respectively, as compared with SC, implying that both SDD and SOD are dominant (ie, cheaper and more beneficial) over SC. In cost-effectiveness acceptability curves probabilities for cost-effectiveness, compared with standard care, ranged from $89 \%$ to $93 \%$ for SOD and from $63 \%$ to $72 \%$ for SDD, for acceptable costs for 1 LYG ranging from $€ 0$ to $€ 20000$. Sensitivity analysis for mechanical ventilation and discount rates did not change interpretation. Yet, if costs of the topical component of SDD and SOD would increase 40-fold to $€ 400 /$ day and $€ 40 /$ day (maximum values based on free market prices in 2012), the estimated ICER as compared with SC for SDD would be $€ 21590$ per LYG. SOD would remain cost-saving.

Conclusions: SDD and SOD were both effective and cost-saving in Dutch ICUs.

\section{ARTICLE SUMMARY}

Article focus

- Selective digestive tract decontamination (SDD) and selective oropharyngeal decontamination (SOD) are prophylactic antibiotics used as infection prevention strategy in intensive care units (ICU).

- In a Dutch 13-centre study, SDD and SOD were associated with relative risk reductions of mortality at day 28 of $13 \%$ and $11 \%$, respectively, as compared with standard care (SC; ie, no SDD or SOD) and with lower incidence of ICU-acquired bacteraemia and ICU-acquired colonisation of the respiratory tract with multiresistant bacteria.

- This paper describes the costs and effects of SDD and SOD from the healthcare perspective in Dutch ICUs.

Key messages

- Both SDD and SOD were cheaper and more beneficial as compared with SC and these findings were insensitive to changes in discount rates and extra costs for ventilation days.

- SOD, but not SDD, was still dominant (ie, cheaper and more beneficial) over SC to current 40-fold higher market-prices of the topical components (€40/day for SOD and $€ 400 /$ day for SDD).

Strengths and limitations of this study

- This is the first head-to-head comparison of the costs and benefits of SDD and SOD and the first comparison of both interventions versus SC using data from a multicentre trial including 5939 patients.

- Baseline differences were present between the three study groups.

- Only direct medical costs were included in the analysis and cost data were restricted to healthcare settings. 


\section{INTRODUCTION}

Many patients in Intensive Care Units (ICU) are affected by nosocomial infections. ${ }^{1}$ These infections are associated with increased mortality and morbidity, and considerable extra expenditure. ${ }^{2}$ Selective oropharyngeal decontamination (SOD) and selective decontamination of the digestive tract (SDD) are prophylactic antibiotic regimens, that consist of topical antibiotics applied to the oropharynx and the intestinal tract to prevent colonisation of Gram-negative bacteria, Staphylococcus aureus and yeasts. During SOD topical antibiotics are exclusively applied to the oropharynx throughout the ICU-stay. During SDD topical antibiotics are not only applied to the oropharynx but also to the intestinal tract throughout the ICU-stay, in combination with intravenous administration of cefotaxime during the first 4 days in ICU, to pre-emptively treat infections with commensal respiratory tract bacteria. ${ }^{3}$ SDD has been a widely evaluated but highly controversial intervention in ICU. ${ }^{4}$ Many, but not all, studies reported statistically significant reductions in the incidence of Ventilator-Associated Pneumonia (VAP), but only few were able to demonstrate outcome benefits such as reduced mortality and length of ICU-stay. ${ }^{5}$ In the absence of indisputably documented outcome benefits, the fear for selection of antibiotic resistance has prevailed and SDD has not been recommended in most infection prevention guidelines. $^{6-9}$ In a cluster-randomised study in 13 Dutch ICUs, SDD and SOD were associated with relative risk (RR) reductions of mortality on day 28 of $13 \%$ and $11 \%$, respectively, as compared with standard care $(\mathrm{SC}$; ie, no SDD or SOD). ${ }^{3}$ Although SOD and SDD are currently widely used in Dutch ICUs, the costs and effects of both regimens have not yet been determined. We, therefore, conducted a cost-effectiveness analysis (CEA), comparing SC, SOD and SDD using data from the Dutch multicentre trial.

\section{METHODS}

\section{Data collection}

A post hoc analysis of the cluster randomised crossover trial comparing SOD and SDD to SC was performed. The trial was conducted in 13 Dutch ICUs and included 5939 patients (2045 received SDD, 1904 received SOD and 1990 were treated according to SC). All centres were assigned to all three regimens during periods of 6 months; however, the order of implementation of SC, SOD and SDD was randomised per centre. ${ }^{3}$

SOD and SDD have been described in detail elsewhere. ${ }^{3}$ In short, SOD consists of a paste applied to the oropharynx, containing polymyxin E, tobramycin and amphotericin B (all in a $2 \%$ concentration, applied every $6 \mathrm{~h}$ ). SDD consists, besides the paste used in SOD, also of a $10 \mathrm{ml}$ suspension of $100 \mathrm{mg}$ polymyxin $\mathrm{E}$, $80 \mathrm{mg}$ tobramycin and $500 \mathrm{mg}$ amphotericin $\mathrm{B}$ that is applied via a nasogastric tube, every $6 \mathrm{~h}$, and of cefotaxime (1000 mg, every $6 \mathrm{~h}$ ) applied intravenously during the first 4 days of ICU-admission. The topical antibiotics of both regimens are applied until ICU-discharge. During the trial there were no restrictions to systemic antibiotic use during SC and SOD. During SDD, the use of antibiotics with antianaerobic activity was discouraged. This resulted in a marked increase of cephalosporin use and lower usage of penicillins, carbapenem and clindamycin. ${ }^{3}$ Surveillance cultures of endotracheal aspirates, oropharynx and rectum were obtained upon admission and twice weekly during SDD. During SOD surveillance, cultures of endotracheal aspirates and the oropharynx were obtained upon admission and twice weekly thereafter. During SC no surveillance cultures were obtained. Clinical cultures were obtained on clinical suspicion of infection in all three periods.

\section{Approach for economic evaluation}

We performed a CEA from a healthcare perspective, hence, only including direct medical costs. ${ }^{10-12}$ The time horizon of the study was the period from ICU-admission until hospital-discharge. Life Years Gained (LYG) was used as effectiveness measure. The outcome of the CEA was the incremental cost effectiveness ratio (ICER), expressed as cost per LYG. The informal Dutch threshold for cost-effectiveness is €20 000/ LYG. ${ }^{13}$ Data from all individual patients were used for analyses. The CEA was performed post hoc, however, using data that were prospectively collected in Case Report Forms during the trial. Total direct medical costs of the three regimens consisted of three main categories: Length of Stay (LOS), antibiotic use and microbiology costs (table 1). LOS was based on the length of ICU-stay and the number of days on a hospital ward after ICU-discharge. Costs for days in ICU and other hospital days were based on the Dutch guidelines for costing research in health economic studies. ${ }^{11}$ Days in ICU were categorised in days with and without mechanical ventilation; days with mechanical ventilation were considered to be $15 \%$ more expensive than ICU-days without mechanical ventilation. ${ }^{15-17}$ Antibiotic use consisted of the topical components of the SDD-regimen and SOD-regimen, hereafter referred to as study medication, and of all systemic antibiotics used in ICU during all periods, including the 4 days cefotaxime during SDD as part of the SDD-protocol. The price of study medication was $€ 0.87$ and $€ 10.48 /$ day, for SOD and SDD, respectively. Costs of systemic antibiotics were based upon prices per Defined Daily Dose (DDD) provided by the Dutch information project on medication and medical devices (Genees- en hulpmiddelen Informatie Project (GIP)-database ${ }^{18}$ ). For microbiology costs blood cultures, broncheoalveolar lavages, sputum, throat and rectal cultures were considered. Rectal cultures were only obtained during SDD as part of SDD-surveillance. Cultures obtained from the other sites were either obtained as part of the surveillance (throat and sputum cultures during SDD/SOD) or as part of daily clinical practice. Microbiological costs were obtained as the 


\section{Table 1 Costs used per unit}

\begin{tabular}{|c|c|}
\hline Category & Prices per unit \\
\hline \multicolumn{2}{|l|}{ Length of stay } \\
\hline Day in ICU & $€ 2183^{11}$ \\
\hline Day in hospital ward & $€ 505^{11}$ \\
\hline Mechanical ventilation, additional costs & $€ 327.45^{15-17}$ \\
\hline \multicolumn{2}{|l|}{ Topical antibiotics } \\
\hline Cost of SOD per day & $€ 0.87^{342}$ \\
\hline Cost of SDD per day & $€ 10.48^{342}$ \\
\hline \multicolumn{2}{|l|}{ Microbiology } \\
\hline Blood culture & $€ 11.89$ per culture $+€ 12.90$ order rate ${ }^{\star}$ \\
\hline Throat culture & $€ 7.78$ per culture $+€ 12.90$ order rate* \\
\hline Sputum culture & $€ 7.78$ per culture $+€ 12.90$ order rate* \\
\hline Bronchoalveolar lavage & $€ 7.78$ per sample $+€ 12.90$ order rate* \\
\hline Rectum culture & $€ 7.78$ per sample $+€ 12.90$ order rate* \\
\hline Species determination & Extra $€ 13.00$ per isolate $+€ 18.52^{*}$ \\
\hline Resistance profile determination & 8.96 per isolate \\
\hline Antibiotics & According to GIP database ${ }^{18}$ \\
\hline
\end{tabular}

internal tariffs applied within the University Medical Center, Utrecht. These costs included costs for the microbiological culture, order tariff and extra costs for species determination and susceptibility resistance testing in case of relevant bacterial growth, irrespective of the species. The year 2009 was taken as the reference year for all costs. Costs that were not available for 2009 were corrected for inflation (with respect to 2009) based on the price index. ${ }^{11}$ An overview of all unit costs used in the analysis is provided in table 1. LYG were discounted at $1.5 \%$ a year, following Dutch guidelines for health economic evaluation. ${ }^{19}$ Discounting of costs was not necessary, as all costs occurred within the first year after inclusion. ${ }^{20}$

\section{Analysis}

LYG were determined by calculating Life Years Lost (LYL) of the patients who deceased in the hospital, using life tables for the Dutch population combined with age and sex, ${ }^{21}$ with LYG defined as the difference in LYL between regimens. The ICER was defined as the incremental difference between the mean cost of treatment regimens, divided by the incremental difference in mean effect between treatment regimens. To estimate confidence limits for the ICER, bootstrapping (25000 repeats) was performed, as this does not depend on parametric assumptions about the distribution of the data. $^{22} 23$ Results of the bootstrap procedure were plotted in a cost-effectiveness plane that graphically represents the cost-difference and effect difference between either SDD or SOD and SC, and for SDD versus SOD, for each of the bootstrap replications. Cost-effectiveness acceptability curves (CEAC) were plotted to express the probability that treatment regimens were cost-effective as compared with SC, for a range of willingness to pay levels for one LYG $(\lambda) .{ }^{24}$ The curves display the proportion of bootstrapped ICER-pairs that are cost-effective, meaning that they either fall within the south-east quadrant of the costeffectiveness plane or remain below the $\lambda$ threshold in the north-east and south-west quadrants of the plane. In addition, sensitivity analyses were performed: the discounted results (at $1.5 \%$ a year) were compared with results without discounting and to a discount rate of $3 \%$ a year; costs for ICU-days with mechanical ventilation were analysed for $0 \%$ and $30 \%$ extra per ICU-day as compared with $15 \%$ additional costs in base case analysis; daily costs of study medication were analysed with maximum values based upon free market prices in 2012 ( $€ 40$ for SOD and $€ 400$ for SDD). Mann-Whitney $U$ test was used to calculate $p$ values. $p$ Value $<0.05$ was considered to denote statistical significance and all reported $\mathrm{p}$ values are two-sided. All analyses were performed using Statistical Package for Social Sciences V.20 (SPSS, Chicago, Illinois, USA) V.17.0 and R V.2.14.2.

\section{RESULTS}

In this cluster-randomised trial 5939 patients were included; 1990 patients in the SC group, 1904 received SOD and 2045 received SDD. For this post hoc analysis, 19 patients were excluded (3 patients during SC, 3 during SOD and 13 during SDD). Twelve patients declined permission to use clinical data. Seven additional patients were excluded because data on hospital discharge and/or hospital mortality was missing, as reported previously. ${ }^{3}$

Baseline characteristics differed among the three groups (table 2). Patients receiving SDD were on average $62.4( \pm 15.8)$ years old, compared with 61.4 $( \pm 16.3)$ and $61.4( \pm 16.2)$ years for patients receiving 
Table 2 Baseline characteristics, clinical outcomes and resource use of patients

\begin{tabular}{|c|c|c|c|}
\hline & $\begin{array}{l}S C \\
N=1987\end{array}$ & $\begin{array}{l}\text { SOD } \\
N=1901\end{array}$ & $\begin{array}{l}\text { SDD } \\
\mathrm{N}=2032\end{array}$ \\
\hline \multicolumn{4}{|l|}{ Baseline characteristics } \\
\hline Age (years) (mean (SD)) ${ }^{\star * * * *}$ & $61.4 \pm 16.2$ & $61.4 \pm 16.3$ & $62.4 \pm 15.8$ \\
\hline Male sex (no (\%)) & $1219(61.3)$ & $1211(63.7)$ & $1242(63.7)$ \\
\hline Apache II score $(\text { mean }(S D))^{*},{ }^{\star *}$ & $18.6 \pm 7.9$ & $19.6 \pm 8.8$ & $19.9 \pm 8.9$ \\
\hline Mechanical ventilation (no $(\%))^{\star},{ }^{\star *}$ & $1751(88.1)$ & $1790(94.2)$ & $1888(92.9)$ \\
\hline \multicolumn{4}{|l|}{ Clinical outcome } \\
\hline Length of MV (days) (median (IQR)) & $6(9)$ & $7(8)$ & $6(9)$ \\
\hline Length of stay ICU (days) (median (IQR)) & $8(11)$ & $9(9)$ & $9(10)$ \\
\hline Length of stay hospital (days) (median (IQR))‡ & $15(23)$ & $15(22)$ & $15(21)$ \\
\hline \multicolumn{4}{|l|}{ Resource use } \\
\hline Study medication (DDD) (total (mean)) & 0 & $7609(4.0)$ & 8068 (3.95) \\
\hline Systemic antibiotics (DDD) (total (mean)) & $33688(5.9)$ & $30299(6.2)$ & $29663(5.2)$ \\
\hline \multicolumn{4}{|l|}{ Microbiology (total (mean)) } \\
\hline Rectal & 0 & 0 & $7247(3.8)$ \\
\hline BAL & $263(1.3)$ & $221(1.3)$ & $253(1.3)$ \\
\hline Sputum & $5430(3.7)$ & $7467(4.3)$ & $8073(4.4)$ \\
\hline Throat & $431(2.7)$ & $6277(3.5)$ & $7176(3.8)$ \\
\hline Blood & $4113(3.7)$ & $4849(4.1)$ & $4461(4.1)$ \\
\hline
\end{tabular}

SOD and SC, respectively. Patients receiving SC had a lower mean APACHE II score (18.6) than those receiving SOD (19.6) and SDD (19.9), and were less likely to be on mechanical ventilation $(88.1 \%$ for $\mathrm{SC}$ vs $94.2 \%$ and $92.9 \%$ for SOD and SDD, respectively).

Mean LOS in ICU and in hospital and mean duration of mechanical ventilation did not differ significantly between SC, SOD and SDD. These data differ somewhat from original LOS data reported previously, ${ }^{3}$ which included only data of patients who were alive on day 28 .

In all, 7609 daily doses of study medication were used in the SOD group and 8068 during SDD, with average numbers of 4 doses/day for SOD patients and 3.95 for SDD patients. The average number of DDD of systemic antibiotics during ICU-stay was the lowest during SDD with absolute numbers of 33688 DDDs during SC, 30299 during SOD and 29663 during SDD.

\section{Cost analysis}

Average total costs per patient were €41 941 for SC $(95 \%$ CI $€ 40184$ to $€ 43698$ ), $€ 40433$ for SOD (95\% CI €38 838 to $€ 42029$ ) and $€ 41183$ for SDD (95\% CI $€ 39408$ to $€ 42$ 958) (table 3). LOS accounted for approximately $98 \%$ of total costs, and these costs were the highest for patients during SC. Mean costs per patient for study medication were $€ 3.48$ and $€ 41.35$ during SOD and SDD, respectively. Mean costs of systemic antibiotics per patient were $€ 358.29$ (95\% CI €321.34 to €395.24) during SC, €317.65 (95\% CI $€ 280.89$ to $€ 354.42)$ during SOD and $€ 439.14 \quad(95 \%$ CI $€ 406.69$ to $€ 471.59$ ) during SDD ( $\mathrm{p}<0.01$ for SDD vs SC and SOD). Mean costs for microbiology cultures were the highest for SDD (€ 371.72), as compared with SOD $(€ 287.27)$ and SC $(€ 220.05$; $<<0.01$ for SDD vs SC and SOD).

Hospital mortality was $31.8 \%, 30.7 \%$ and $32.3 \%$ during SC, SOD and SDD, respectively. The difference in hospital mortality for SDD, as compared with reported mortality previously ${ }^{3}(32.3 \%$ vs $32.6 \%)$, results from inclusion of outcome data from the 12 patients that declined permission to use clinical (not mortality) data in the main analysis. Estimated LYL were, on average, 6.07 years for SC patients, 5.62 years for SOD patients and 5.97 years for SDD patients. Effects were discounted with $1.5 \%$ a year resulting in LYG of +0.25 years for SOD and +0.04 years for SDD as compared with SG (table 4). SOD resulted in +0.21 LYG when compared with SDD. In the cost-effectiveness plane, point estimates of the differences in costs and effects indicated that both SOD and SDD were beneficial and cheaper (ie, south-east quadrant) over SC. As depicted in figure 1, SOD and SDD were dominant (ie, southeast quadrant of plane) in $77.5 \%$ and $40.1 \%$ of the bootstrap estimates, respectively. When comparing SOD versus SDD, SOD dominates SDD in $60.2 \%$ of the bootstrap replicates. If only cost aspects were taken into account (ie, combining the south-east and south-west quadrants), $89.3 \%$ and $72.4 \%$ of the bootstrap replicates were cheaper than SC during SOD and SDD, respectively. In addition, bootstrap results were graphically displayed in CEAC showing the probability that a treatment is cost-effective in comparison with another treatment, given a certain threshold value for the willingness to pay 
Table 3 Total costs $(2009 €)$ per patient

\begin{tabular}{|c|c|c|c|}
\hline & $\begin{array}{l}\text { SC } \\
N=1990\end{array}$ & $\begin{array}{l}\text { SOD } \\
N=1904\end{array}$ & $\begin{array}{l}\text { SDD } \\
\mathrm{N}=2045\end{array}$ \\
\hline \multicolumn{4}{|l|}{ Length of stay } \\
\hline ICU & $\begin{array}{l}€ 29553.45(€ 28152.40 \\
\text { to } € 30954.49)\end{array}$ & $\begin{array}{l}€ 28684.46(€ 27412.05 \\
\text { to } € 29956.87)\end{array}$ & $\begin{array}{l}€ 29069.78(€ 27636.40 \\
\text { to } € 30503.16)\end{array}$ \\
\hline Hospital & $€ 8621.85$ ( $€ 8059.10$ to $€ 9184.61)$ & $€ 7830.55$ ( $€ 7345.91$ to $€ 8315.20)$ & $€ 7963.94$ (€7476.75 to $€ 8451.13)$ \\
\hline MV & $€ 3225.06$ (€3045.61 to $€ 3404.51)$ & $€ 3316.36$ (€3151.14 to $€ 3481.58)$ & $€ 3308.18$ (€3116.09 to $€ 3500.27)$ \\
\hline Total & $\begin{array}{l}€ 41400.36(€ 39672.04 \\
\text { to } € 43128.68)\end{array}$ & $\begin{array}{l}€ 39831.37(€ 38261.92 \\
\text { to } € 41400.82)\end{array}$ & $\begin{array}{l}€ 40341.90(€ 38599.66 \\
\text { to } € 42084.14)\end{array}$ \\
\hline Study medication & - & $€ 3.48(€ 3.47$ to $€ 3.49)$ & $€ 41.35$ (€41.07 to $€ 41.62)^{\star}$ \\
\hline Systemic & $€ 358.29$ (€321.34 to $€ 395.24)$ & $€ 317.65$ (€280.89 to $€ 354.42)$ & $€ 439.14$ (€406.69 to $€ 471.59)$ \\
\hline \multicolumn{4}{|l|}{ Antibiotics } \\
\hline \multicolumn{4}{|l|}{ Microbiology } \\
\hline Rectal swabs & - & - & $€ 102.75$ (€97.64 to $€ 107.86)$ \\
\hline BAL & $€ 6.44$ (€5.42 to $€ 7.46)$ & $€ 4.70$ (€3.92 to $€ 5.49)$ & $€ 4.77(€ 4.01$ to $€ 5.53)$ \\
\hline Sputum & $€ 114.83(€ 106.87$ to $€ 122.79)$ & $€ 135.85(€ 127.99$ to $€ 143.71)$ & $€ 117.57$ (€110.78 to $€ 124.36)$ \\
\hline Throat & $€ 8.12$ (€6.39 to $€ 9.84)$ & $€ 86.66$ (€83.07 to $€ 90.25)$ & $€ 89.65$ (€85.68 to $€ 93.63)$ \\
\hline Blood & $€ 52.61$ (€48.74 to $€ 56.49)$ & $€ 53.72$ (€49.64 to $€ 57.79)$ & $€ 45.45$ (€41.87 to $€ 49.04)$ \\
\hline Total & $€ 182.15$ (€170.60 to $€ 193.69)$ & $€ 280.93$ (€267.00 to $€ 294.87)$ & $€ 360.73$ (€343.69 to $€ 377.76)$ \\
\hline Total & $\begin{array}{l}€ 41940.79(€ 40183.93 \\
\text { to } € 43697.66)\end{array}$ & $\begin{array}{l}€ 40433.42(€ 38837.50 \\
\text { to } € 42029.35)\end{array}$ & $\begin{array}{l}€ 41183.12(€ 39408.39 \\
\text { to } € 42957.85)\end{array}$ \\
\hline
\end{tabular}

for one LYG. These probabilities varied for values ranging from $€ 0$ to $€ 20000$, between $89 \%$ and $93 \%$ for SOD and between $63 \%$ and $72 \%$ for SDD (figure 1). For SOD versus SDD, these probabilities varied from $73 \%$ to $87 \%$.

In the cost-analysis, $€ 69.59$ per 1 DDD of cefotaxime was used as reference price ${ }^{18}$ and average costs of systemic antibiotics were the highest during SDD. ${ }^{3}$ The price of 1 DDD cefotaxime should be $€ 39.37$ and $€ 19.07$ to balance costs for systemic antibiotics between SDD and SC and SDD and SOD, respectively.

Sensitivity analyses on mechanical ventilation costs and discount rates did not change the interpretation of results (table 5, figure 1 ). Yet, daily costs of $€ 10$ and $€ 400$ for study medication in SOD and SDD resulted in an ICER of $€ 21590$ per LYG for SDD versus SC whereas SOD remained dominant over SC. For all situations, SOD was more effective and cheaper than SDD (table 4 and 5). To stay below the Dutch threshold of $€ 20000$ per LYG, the maximum daily price for the topical SDD-components should be $€ 375$.

\section{DISCUSSION}

This post hoc analysis of a large cluster-randomised trial performed in 13 Dutch ICUs including 5920 patients revealed that both SOD and SDD are cost-saving and more effective as compared with SC. These findings were insensitive to changes in discount rates and extra expenses for ventilation days. Furthermore, for SOD, but not for SDD, these findings were insensitive to current (higher) market-prices of the topical components. The probabilities that SOD and SDD are cost-effective for a willingness to pay threshold of $€ 20000$ per LYG as compared with SC, were $93 \%$ and $63 \%$, respectively.

This is the first head-to-head comparison of the costs and benefits of SDD and SOD and the first comparison of both interventions versus SC. Strengths of the present study include the large study size and the completeness of data collection.

Limitations of the study are the baseline differences between the three study periods. Patients receiving SC were younger, had lower APACHE II scores and were less likely to receive mechanical ventilation and, therefore,

Table 4 Outcomes of cost-effectiveness comparisons across groups

\begin{tabular}{llll}
\hline & LYG* & Cost difference & ICER \\
\hline SOD v SC $(95 \% \mathrm{Cl})$ & $+0.25(-0.05$ to 0.55$)$ & $-€ 1507.37(-€ 3186.45$ to $€ 171.72)$ & SOD dominates SC \\
SDD vs SC $(95 \% \mathrm{Cl})$ & $+0.04(-0.26$ to 0.34$)$ & $-€ 757.67(-€ 2522.56$ to $€ 1007.21)$ & SDD dominates SC \\
SOD vs SDD $(95 \% \mathrm{Cl})$ & $+0.21(-0.09$ to 0.51$)$ & $-€ 749.69(-€ 2439.35$ to $€ 939.97)$ & SOD dominates SDD \\
\hline
\end{tabular}

${ }^{*}$ Effects are discounted at $1.5 \%$ a year.

ICER, incremental costs effectiveness ratio (costs/LYG); LYG, life years gained; SC, Standard Care; SDD, Selective Decontamination of the Digestive tract; SOD, Selective Oropharyngeal Decontamination. 
Figure 1 Scatterplot of incremental cost-effectiveness ratio pairs based on the results of bootstrap resampling technique (25 000 replicates) and cost-effectiveness acceptibility curves for (A and B) SOD vs SC, ( $C$ and $D$ ) SDD vs SC and ( $E$ and F) SOD vs SDD. SOD, selective oropharyngeal decontamination ; SDD selective decontamination of the Digestive tract; SC, standard care.
A

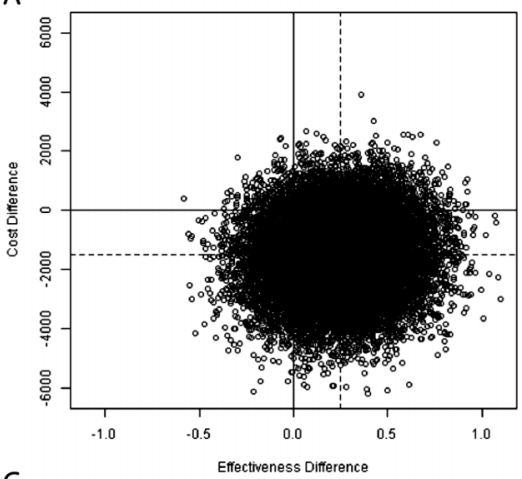

C

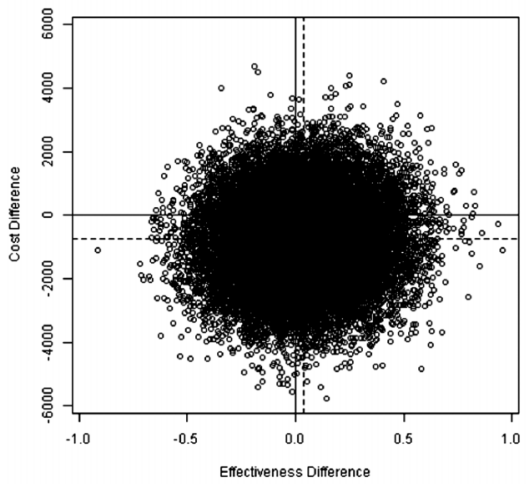

$\mathrm{E}$

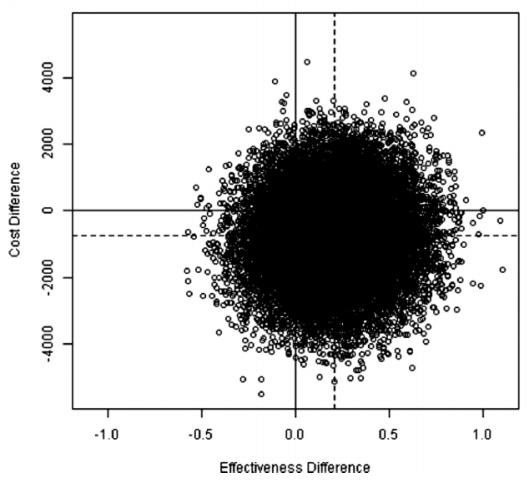

B

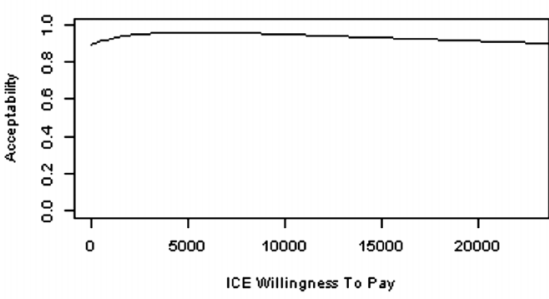

D

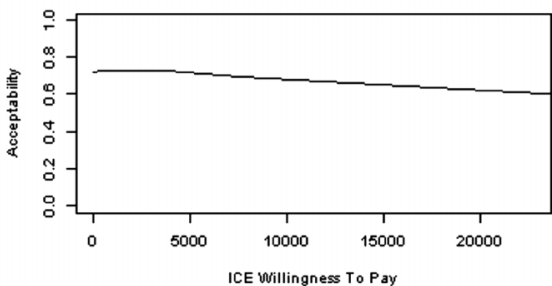

$\mathrm{F}$

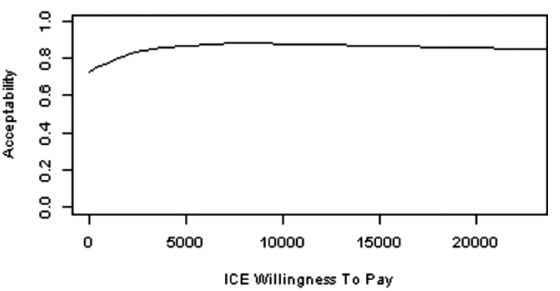

seemed to have a better prognosis. In the original trial random effects logistic regression modelling was applied to adjust for these differences. ${ }^{3}$ Here we have used crude data, without any adjustments for baseline differences. Our analysis points at superiority of SOD and SDD when compared with SC, despite the somewhat more favourable prognosis at the time of ICU-admission of patients receiving SC. Our findings on the costeffectiveness of both interventions are, therefore, conservative estimates. Furthermore, patients receiving SOD were, on average, 1 year younger than those receiving SDD, which may have affected the difference in LYL between both interventions. Other limitations are the restriction of cost data to the healthcare setting and the absence of antibiotic and microbiology cost data after ICU-discharge, which could not be obtained retrospectively. Finally, this trial was performed in ICU-settings with low endemicity of antibiotic resistance, which may limit generalisability to other settings.
The main contributor to the total costs was LOS, which was composed of stay in ICU and hospital after ICU-discharge. The other costs, microbiology and antibiotics, were the highest for SDD, which had been reported previously. ${ }^{25}$ Some relatively small single-centre studies, also determined the effects of SDD on costs of days in ICU or in the hospital. In a German study SOD with cefotaxime prophylaxis resulted in lower average costs for antibiotic therapy and for days on ventilation than during SC. ${ }^{26}$ In a French study of trauma patients both daily ICU-costs as well as mean antibiotic costs, including SDD treatment, were lower during SDD compared with SC. ${ }^{27}$ In a Spanish study mean costs of systemic antibiotics were lower and less diagnostic procedures for infections were performed during SDD, compared with those during SC, which resulted in a $21 \%$ reduction of total costs per survivor in the SDD-treated group. ${ }^{28}$ Yet, in none of these studies a formal CEA was performed. 


\begin{tabular}{|c|c|c|c|c|c|c|}
\hline & SC & SOD & SDD & $\begin{array}{l}\text { ICER analyses } \\
\text { SC vs SOD }\end{array}$ & $\begin{array}{l}\text { ICER analyses } \\
\text { SC vs SDD }\end{array}$ & $\begin{array}{l}\text { ICER analyses } \\
\text { SDD vs SOD }\end{array}$ \\
\hline \multicolumn{7}{|c|}{ Sensitivity analysis discounting effects (life years lost) } \\
\hline $\mathrm{BC}+1.5 \%$ & 4.27 (3.96 to 4.57$)$ & 4.02 (3.72 to 4.32$)$ & 4.23 (3.94 to 4.53$)$ & $\begin{array}{l}\mathrm{SC}=\text { dominated by } \\
\mathrm{SOD}\end{array}$ & $\begin{array}{l}\mathrm{SC}=\text { dominated by } \\
\mathrm{SDD}\end{array}$ & $\begin{array}{l}\text { SDD=dominated by } \\
\text { SOD }\end{array}$ \\
\hline$+0 \%$ & 6.07 (5.58 to 6.55$)$ & $5.62(5.15$ to 6.08$)$ & 5.97 (5.50 to 6.44$)$ & $\begin{array}{l}\text { SC=dominated by } \\
\text { SOD }\end{array}$ & $\begin{array}{l}\text { SC=dominated by } \\
\text { SDD }\end{array}$ & $\begin{array}{l}\text { SDD =dominated by } \\
\text { SOD }\end{array}$ \\
\hline$+3 \%$ & $2.82(2.63$ to 3.01$)$ & 2.68 (2.49 to 2.87$)$ & $2.82(2.63$ to 3.00$)$ & $\begin{array}{l}\text { SC=dominated by } \\
\text { SOD }\end{array}$ & $\begin{array}{l}\text { SC=dominated by } \\
\text { SDD }\end{array}$ & $\begin{array}{l}\text { SDD=dominated by } \\
\text { SOD }\end{array}$ \\
\hline \multicolumn{7}{|l|}{$\begin{array}{l}\text { Sensitivity analysis } \\
\text { mechanical ventilation } †\end{array}$} \\
\hline $\mathrm{BC}+15 \%$ & $\begin{array}{l}€ 41940.79(€ 40183.93 \\
\text { to } € 43697.66)\end{array}$ & $\begin{array}{l}€ 40433.42(€ 38837.50 \\
\text { to } € 42029.35)\end{array}$ & $\begin{array}{l}€ 41183.12(€ 39408.39 \\
\text { to } € 42957.85)\end{array}$ & $\begin{array}{l}\text { SC=dominated by } \\
\text { SOD }\end{array}$ & $\begin{array}{l}\text { SC=dominated by } \\
\text { SDD }\end{array}$ & $\begin{array}{l}\text { SDD=dominated by } \\
\text { SOD }\end{array}$ \\
\hline$+0 \%$ & $\begin{array}{l}€ 38715.73(€ 37112.32 \\
\text { to } € 40319.14)\end{array}$ & $\begin{array}{l}€ 37117.07(€ 35659.90 \\
\text { to } € 38574.24)\end{array}$ & $\begin{array}{l}€ 37874.94(€ 36270.73 \\
\text { to } € 39479.15)\end{array}$ & $\begin{array}{l}\text { SC=dominated by } \\
\text { SOD }\end{array}$ & $\begin{array}{l}\text { SC=dominated by } \\
\text { SDD }\end{array}$ & $\begin{array}{l}\text { SDD=dominated by } \\
\text { SOD }\end{array}$ \\
\hline$+30 \%$ & $\begin{array}{l}€ 45165.85(€ 43251.01 \\
\text { to } € 47080.69)\end{array}$ & $\begin{array}{l}€ 43749.78(€ 42010.47 \\
\text { to } € 45489.09)\end{array}$ & $\begin{array}{l}€ 44491.30(€ 42542.03 \\
\text { to } € 46440.57)\end{array}$ & $\begin{array}{l}\text { SC=dominated by } \\
\text { SOD }\end{array}$ & $\begin{array}{l}\text { SC=dominated by } \\
\text { SDD }\end{array}$ & $\begin{array}{l}\text { SDD=dominated by } \\
\text { SOD }\end{array}$ \\
\hline $\begin{array}{l}\text { Sensitivity analysis price } \\
\text { study regimen* } \dagger\end{array}$ & $\begin{array}{l}€ 41940.79(€ 40183.93 \\
\text { to } € 43697.66)\end{array}$ & $\begin{array}{l}€ 40493.15(€ 38996.62 \\
\text { to } € 42189.67)\end{array}$ & $\begin{array}{l}€ 42720.23(€ 40943.82 \\
\text { to } € 44.496 .65)\end{array}$ & $\begin{array}{l}\text { SC=dominated by } \\
\text { SOD }\end{array}$ & ICER 21590 & $\begin{array}{l}\text { SDD=dominated by } \\
\text { SOD }\end{array}$ \\
\hline
\end{tabular}


VAP incidences were not determined in the Dutch SDD-SOD trial ${ }^{3}$ because of the perceived difficulties in uniformly diagnosing VAP in 13 ICUs. Yet, both SDD and SOD have been associated with reduced incidences of VAP, as compared with SC. ${ }^{59}$ In addition to SDD and SOD there are other preventive measures that have been associated with reductions in the incidence of VAP, such as the use of silver-coated endotracheal tubes and continuous subglottic suctioning (CSS). In a large multicentre randomised controlled trial silver-coated endotracheal tubes were associated with an RR reduction of the incidence of VAP of $35.9 \%$, without discernible beneficial effects on patient outcome. ${ }^{30}$ In a CEA of this trial the use of silvercoated tubes, although 45-fold more expensive than normal tubes ( $\$ 90$ vs $\$ 2$ per tube), yielded savings of $\$ 12840$ per episode of VAP prevented. ${ }^{31}$ CSS was, in a recent meta-analysis of 13 randomised trials, associated with a $45 \%$ reduction in the incidence of VAP (RR 0.55 (95\% CI 0.46 to 0.66 ), but also without discernible beneficial effects on patient outcome (RR 1.01 (95\% CI 0.85 to 1.20). ${ }^{32}$ The intervention appeared cost saving in two studies, saving $\$ 4992$ and $€ 1176$ per episode of VAP prevented. ${ }^{33}$ However, these analyses were based on extrapolated costs per episode of VAP, rather than on the true costs generated during the trials. Other widely recommended measures to prevent VAP, such as the semirecumbent patient position and different bundle approaches have not been associated with documented improvements in patient outcome and have not been evaluated with formal cost-effectiveness analyses.

In conclusion, both SOD and SDD appeared more beneficial and cost saving as compared with SC and even if the costs of both measures would increase 40-fold SOD will remain cost-saving and the ICER of SDD will be around the Dutch threshold for costeffectiveness of $€ 20000$ per LYG. The higher price for medication follows from the higher costs for amphotericine $\mathrm{B}$, which could be alleviated by replacing amphotericine $\mathrm{B}$ by nystatin, which has also good antifungal activity in topical application. ${ }^{35}$ With 1180 ICU-beds in a country of 16.6 million inhabitants (year 2010), extrapolation of our findings suggests that nationwide implementation of SOD or SDD in ICUs, as occurred after the trial, has saved, per year, 18-36 million Euros.

The Dutch multicentre study on SDD and SOD provided evidence of better patient outcome, ${ }^{3}$ lower antibiotic resistance prevalence in the ICUs, ${ }^{36}$ lower incidence of ICU-acquired bacteraemia and ICU-acquired colonisation of the respiratory tract with multiresistant bacteria, ${ }^{37}$ effective eradication of intestinal carriage with cephalosporinresistant Enterobacteriaceae, ${ }^{38}$ and low rates of resistance development to colistin. ${ }^{39}$ Importantly, these beneficial effects were obtained in ICUs with low levels of antibiotic resistance, reflected by incidence rates of bloodstream infections caused by methicillin-resistant $S$ aureus, vancomycin-resistant enterococci and highly-resistant Enterobacteriaceae of $<0.1,<0.1$ and 0.5 per 1000 patient at risk, respectively. ${ }^{37}$ Whether these benefits can be realised in ICUs with different bacterial ecology remain to be determined, ${ }^{40}$ but given the potential gains careful scientific evaluation is warranted. ${ }^{41}$

Author affiliations

${ }^{1}$ Department of Medical Microbiology, University Medical Center Utrecht, Utrecht, The Netherlands

${ }^{2}$ Department of Intensive Care Medicine, University Medical Center Utrecht, Utrecht, The Netherlands

${ }^{3}$ Julius Center for Health Sciences and Primary Care, University Medical Center Utrecht, Utrecht, The Netherlands

${ }^{4}$ Center for Infectious Disease Control, National Institute for Public Health and the Environment (RIVM), Bilthoven, The Netherlands

${ }^{5}$ Department of Critical Care, University of Groningen, University Medical Center, Groningen, The Netherlands

Collaborators The Dutch SOD-SDD trialists group include the following persons and sites: Cor J Kalkman, Hans (J) C A Joore, Maurine A. Leverstein-van Hall, Hetty E M Blok, University Medical Center Utrecht, Utrecht; Jan A J W Kluytmans, Nardo J M van der Meer, Amphia Hospital, Breda; Ellen M Mascini, Karin Kaasjager, Frank H Bosch, Rijnstate Hospital, Arnhem; Robin F J Benus, Tjip S van der Werf, Jan P Arends, University Medical Center, Groningen; Johannes G van der Hoeven, Peter Pickkers, Patrick D J Sturm, Andreas Voss, Radboud University, Nijmegen Medical Center, Nijmegen; Alexandra T Bernards, Ed J Kuijper, Hubertus I J Harinck, Leiden University Medical Center, Leiden; Alexander J G H Bindels, Arjan R Jansz, Catharina Hospital, Eindhoven; Ronald M J Wesselink, Bartelt M de Jongh, St Antonius Hospital, Nieuwegein; Paul J W Dennesen, Gerard J van Asselt, Medical Center Haaglanden, The Hague; Leonard F te Velde, Ine H M E Frenay, Albert Schweitzer Hospital, Dordrecht; Mat van Iterson, Steven F T Thijsen,

Diakonessen Hospital, Utrecht; Georg H Kluge, Slotervaart Hospital,

Amsterdam; Jacob W de Vries, Jan A Kaan, Mesos Medical Center, Utrecht-all in the Netherlands.

Contributors AMdS and MJMB conceived the study. EO, AdW and MJMB designed the study. The SDD-SOD trialist group and AMdS collected the trial data. EO, AdW, MB and MJM analysed and interpreted the data. EO, MB and MJMB drafted the manuscript and AdW, AMdS and The SDD-SOD trialist group critically revised the manuscript for important intellectual content. All the authors had full access to the data and approved the final manuscript. EO is the guarantor.

Funding This research received no specific grant from any funding agency in the public, commercial or not-for-profit sectors.

Competing interests None.

Ethics approval Ethical approval for the trial was granted by the institutional review board at each participating hospital, as published previously (NEJM 2009;360:20). The requirement for informed consent was waived.

Provenance and peer review Not commissioned; externally peer reviewed.

Data sharing statement Satistical code is available from the corresponding author.

\section{REFERENCES}

1. Vincent JL. Nosocomial infections in adult intensive-care units. Lancet 2003;361:2068-77.

2. Bearman GM, Munro C, Sessler CN, et al. Infection control and the prevention of nosocomial infections in the intensive care unit. Semin Respir Crit Care Med 2006;27:310-24.

3. de Smet AM, Kluytmans JA, Cooper BS, et al. Decontamination of the digestive tract and oropharynx in ICU patients. $N$ Engl J Med 2009;360:20-31.

4. Wunderink RG. Welkommen to our world. Emergence of antibiotic resistance with selective decontamination of the digestive tract. Am J Respir Crit Care Med 2010;181:426-7.

5. Liberati A, D'Amico R, Pifferi S, et al. Antibiotic prophylaxis to reduce respiratory tract infections and mortality in adults receiving intensive care. Cochrane Database Syst Rev 2009;(4):CD000022.

6. American Thoracic Society. Guidelines for the management of adults with hospital-acquired, ventilator-associated, and healthcare-associated pneumonia. Am J Respir Crit Care Med 2005;171:388-416. 
7. Dodek P, Keenan S, Cook D, et al. Evidence-based clinical practice guideline for the prevention of ventilator-associated pneumonia. Ann Intern Med 2004;141:305-13.

8. Healthcare Infection Control Practices Advisory Committee, Centers for Disease Control and Prevention (U.S.). Guidelines for preventing health-care-associated pneumonia, 2003 recommendations of the $\mathrm{CDC}$ and the Healthcare Infection Control Practices Advisory Committee. Respir Care 2004;49:926-39.

9. Torres A, Carlet J. Ventilator-associated pneumonia. European Task Force on ventilator-associated pneumonia. Eur Respir $J$ 2001;17:1034-45.

10. Drummond MF, Sculpher MJ, Torrance GW, et al. Methods for the economic evaluation of health care programmes. 3rd edn. Oxford: Oxford University Press, 2005.

11. Hakkaart-Van Roijen L, Tan SS, Bouwmans CA. Handleiding voor kostenonderzoek. Methoden en standaard kostprijzen voor economische evaluaties in de gezondheidszorg., 2011.

12. Petrou S, Gray A. Economic evaluation alongside randomised controlled trials: design, conduct, analysis, and reporting. $B M J$ 2011;342:d1548.

13. Boersma C, Carides GW, Atthobari J, et al. An economic assessment of losartan-based versus atenolol-based therapy in patients with hypertension and left-ventricular hypertrophy: results from the Losartan Intervention For Endpoint reduction (LIFE) study adapted to The Netherlands. Clin Ther 2007;29:963-71.

14. Simoens S. Health economic assessment: a methodological primer. Int J Environ Res Public Health 2009;6:2950-66.

15. Al Maiwenn MJ, Hakkaart L, Tan SS, et al. Cost-consequence analysis of remifentanil-based analgo-sedation vs. conventional analgesia and sedation for patients on mechanical ventilation in the Netherlands. Crit Care 2010;14:R195.

16. Dasta JF, McLaughlin TP, Mody SH, et al. Daily cost of an intensive care unit day: the contribution of mechanical ventilation. Crit Care Med 2005;33:1266-71.

17. Tan SS, Hakkaart-van Roijen L, Al MJ, et al. A microcosting study of intensive care unit stay in the Netherlands. J Intensive Care Med 2008;23:250-7.

18. The Dutch Drug Information System of the Health Care Insurance Board. http://www.gipdatabank.nl (accessed 20 March 2012).

19. Gravelle $\mathrm{H}$, Smith $\mathrm{D}$. Discounting for health effects in cost-benefit and cost-effectiveness analysis. Health Econ 2001;10:587-99.

20. De Wit GA, Tariq L, Van Gils PF, et al. Handleiding voor economisch evaluatieonderzoek bij gezondheidsbevordering: Over Euro en Effect, 2010.

21. Centraal Bureau Voor de Statistiek. Levensverwachting; geslacht en leeftijd, 2012.

22. Obenchain RL. Resampling and multiplicity in cost-effectiveness inference. J Biopharm Stat 1999;9:563-82.

23. O'Brien BJ, Briggs AH. Analysis of uncertainty in health care cost-effectiveness studies: an introduction to statistical issues and methods. Stat Methods Med Res 2002;11:455-68.

24. Fenwick E, O'Brien BJ, Briggs A. Cost-effectiveness acceptability curves-facts, fallacies and frequently asked questions. Health Econ 2004:13:405-15.

25. van der Voort PH, van Roon EN, Kampinga GA, et al. A before-after study of multi-resistance and cost of selective decontamination of the digestive tract. Infection 2004;32:271-7.
26. Abele-Horn M, Dauber A, Bauernfeind A, et al. Decrease in nosocomial pneumonia in ventilated patients by selective oropharyngeal decontamination (SOD). Intensive Care Med 1997:23:187-95.

27. Langlois-Karaga A, Bues-Charbit M, Davignon A, et al. Selective digestive decontamination in multiple trauma patients: cost and efficacy. Pharm World Sci 1995;17:12-16.

28. Sanchez Garcia M, Cambronero Galache JA, Lopez Diaz J, et al. Effectiveness and cost of selective decontamination of the digestive tract in critically ill intubated patients. A randomized, double-blind, placebo-controlled, multicenter trial. Am J Respir Crit Care Med 1998;158:908-16.

29. Bergmans DC, Bonten MJ, Gaillard CA, et al. Prevention of ventilator-associated pneumonia by oral decontamination: a prospective, randomized, double-blind, placebo-controlled study. Am J Respir Crit Care Med 2001;164:382-8.

30. Kollef MH, Afessa B, Anzueto A, et al. Silver-coated endotracheal tubes and incidence of ventilator-associated pneumonia: the NASCENT randomized trial. JAMA 2008;300:805-13.

31. Shorr AF, Zilberberg MD, Kollef M. Cost-effectiveness analysis of a silver-coated endotracheal tube to reduce the incidence of ventilator-associated pneumonia. Infect Control Hosp Epidemiol 2009;30:759-63.

32. Muscedere J, Rewa O, McKechnie K, et al. Subglottic secretion drainage for the prevention of ventilator-associated pneumonia: a systematic review and meta-analysis. Crit Care Med 2011;39:1985-91.

33. Hallais C, Merle V, Guitard PG, et al. Is continuous subglottic suctioning cost-effective for the prevention of ventilator-associated pneumonia? Infect Control Hosp Epidemiol 2011;32:131-5.

34. Shorr AF, O'Malley PG. Continuous subglottic suctioning for the prevention of ventilator-associated pneumonia: potential economic implications. Chest 2001:119:228-35.

35. Normand S, Francois B, Darde ML, et al. Oral nystatin prophylaxis of Candida spp. colonization in ventilated critically ill patients. Intensive Care Med 2005;31:1508-13.

36. Oostdijk EA, de Smet AM, Blok HE, et al. Ecological effects of selective decontamination on resistant gram-negative bacterial colonization. Am J Respir Crit Care Med 2010;181:452-7.

37. de Smet AM, Kluytmans JA, Blok HE, et al. Selective digestive tract decontamination and selective oropharyngeal decontamination and antibiotic resistance in patients in intensive-care units: an open-label, clustered group-randomised, crossover study. Lancet Infect Dis 2011:11:372-80.

38. Oostdijk EA, de Smet AM, Kesecioglu J, et al. Decontamination of cephalosporin-resistant Enterobacteriaceae during selective digestive tract decontamination in intensive care units. J Antimicrob Chemother 2012;67:2250-3.

39. Oostdijk EA, Smits L, de Smet AM, et al. Colistin resistance in gram-negative bacteria during prophylactic topical colistin use in intensive care units. Intensive Care Med 2012; 1 Dec 2012 [Epub ahead of print].

40. Walden AP, Bonten MJ, Wise MP. Should selective digestive decontamination be used in critically ill patients? BMJ 2012;345: e6697.

41. Ioannidis JP, Garber AM. Individualized cost-effectiveness analysis. PLOS Med 2011:8:e1001058.

42. Internal Revenue Service. 